\title{
APRBSENTAÇ̄o RBEP
}

https://dx.doi.org/10.24109/2176-6681.rbep.102i262.5152

Prezados(as) leitores(as),

É com prazer que apresentamos o número 262 da Revista Brasileira de Estudos Pedagógicos (RBEP). Esta edição celebra um conjunto de dez artigos científicos, aportados em pesquisas, e dois relatos baseados em experiências educativas. A despeito de suas singularidades, encontraremos nos textos um fio que entretece uma problemática comum: o compromisso com a educação científica, laica, democrática e humana, bem como a sua defesa. Uma feliz sincronia pode ser vislumbrada com o centenário do nascimento do patrono da educação brasileira: Paulo Freire. É que os textos deste número convergem para o que Freire, na relevante e atualíssima obra Educação como prática da liberdade, ensinava à educação e aos educadores: a democracia e a educação democrática se fundam apenas por intermédio da aposta no ser humano e no seu respeito devido; com suas demandas, seus territórios existenciais, seus problemas com a sociedade, seu trabalho, seu País, enfim, com a própria democracia e a defesa da liberdade de pensamento em busca da justiça social, da igualdade de direitos e da emancipação crítica.

Os artigos foram escritos por 30 autores de sete estados brasileiros, representando 16 instituições de educação superior de várias regiões do País. São dez artigos na seção de estudos e dois relatos de experiências. O tema predominante é a docência na educação superior. Os demais textos abordam políticas educacionais, educação infantil e metodologias de ensino. 
Abrimos este número da revista com o artigo "Sistemas Apostilados de Ensino e a autonomia ilusória: reflexões à luz de José Contreras". É um ensaio teórico em que os autores debatem o tema da autonomia docente com base no conceito de autonomia ilusória, de Contreras (2012). Dois argumentos centrais são desenvolvidos no artigo. O primeiro trata da regulação do trabalho do professor, tanto pela escola como pela empresa, afastando-o de aspectos intelectuais, reflexivos e críticos, aproximando seu fazer do modelo de profissional técnico. O segundo diz respeito ao apoio dos docentes ao sistema que os controla, o que leva os autores a evocar o conceito de servidão voluntária, de La Boétie. Os autores concluem que os Sistemas Apostilados de Ensino (SAEs) continuam crescendo com o apoio daqueles que os controlam - os próprios professores.

O segundo artigo intitula-se "Educação, comunicação e imaginação em John Dewey: contribuições teóricas e práticas". Como o próprio título evoca, trata de contribuições teóricas e práticas à educação, considerando o ensino de conteúdos escolares como uma dificuldade concernente à comunicação. Para tal, os autores analisam ideias de John Dewey sobre o significado educacional da comunicação e da imaginação e, também, apresentam uma experiência de um curso de formação de professores, cujo objetivo foi ensinar ideias de Dewey, utilizando as noções de drama e experimento de pensamento. Finalizam argumentando sobre a contribuição do experimento de pensamento para instituir valores fundamentais da prática docente.

Na sequência, temos o artigo "A constituição da identidade docente e suas implicações nas práticas educativas de professores de uma universidade comunitária". Com base em entrevistas sobre trajetória pessoal e profissional feitas com professores(as), as autoras analisam fatores que influenciaram na constituição da sua identidade docente e suas implicações nas práticas educativas. Concluem que o perfil investigativo marca o ingresso dos entrevistados na universidade e que eles apresentam insegurança no que diz respeito aos conhecimentos específicos da docência. A sua constituição e identificação com a profissão de docente são marcadas pelos saberes práticos, resultantes das interações humanas estabelecidas no cotidiano acadêmico. As autoras concluem que um dos desafios para a instituição universitária em questão é criar condições para que tais saberes sejam refletidos criticamente, segundo os referenciais do campo da educação, qualificando, assim, processos de profissionalização dos docentes.

Após, apresentamos o artigo "Docência e relações interculturais na fronteira Brasil-Venezuela", que aborda a interface entre a docência contemporânea e as relações interculturais, mediante análise de oito narrativas de professores de uma escola pública situada na fronteira BrasilVenezuela, a partir da perspectiva pós-estruturalista e dos estudos sobre interculturalidade e docência. Os resultados do estudo evidenciam uma pluralidade de olhares docentes sobre as relações culturais na escola de fronteira, em que a presença de alunos estrangeiros é entendida tanto como uma barreira quanto como uma oportunidade potente de aprendizagem para 
todos. As autoras discutem a possibilidade de uma docência constituída por um ethos fronteiriço, que permita a existência da diferença e da produção de subjetividades dos sujeitos que habitam a escola.

Em "O lugar da educação não escolar nos currículos de Pedagogia", a autora analisa como a dimensão da educação não escolar é abordada nos projetos curriculares do curso de Pedagogia, tendo em vista as diversas exigências formativas estabelecidas pelas Diretrizes Curriculares Nacionais, aprovadas em 2006. A pesquisa apoiou-se em revisão bibliográfica pertinente e em análise de dez projetos pedagógicos do curso de Pedagogia de instituições de ensino superior do Distrito Federal. A autora verifica que as instituições oferecem disciplinas e estágios supervisionados em espaços não escolares. No entanto, tais componentes curriculares estão desconectados da proposta formativa geral, demandando, portanto, propostas curriculares mais efetivas para incorporar a dimensão não escolar na formação de pedagogos(as).

Em seguida, apresentamos o artigo "Autoconfrontação cruzada em grupo focal: recurso metodológico para pesquisas em Educação". As reflexões apresentadas pelas autoras têm como base uma pesquisa sobre a circulação de saberes entre docentes em espaços formativos sistematizados em que se utilizou tal metodologia. A proposta se sustenta, teoricamente, em pressupostos da clínica da atividade (Yves Clot) e em teorizações sobre grupos focais. As autoras consideram que a autoconfrontação cruzada em grupo focal constitui-se numa alternativa relevante para a investigação de temas complexos, como costuma ser o caso na educação, oferecendo, ainda, possibilidades para intervenções de ordem formativa junto aos grupos sociais.

Na sequência, há dois artigos que tratam de políticas educacionais. O primeiro deles, "Anísio Teixeira e o Plano Nacional de Educação - PNE de 1962: qualidade social na construção da pessoa humana e da sociedade", aborda o planejamento educacional concebido por Anísio Teixeira a partir das metas do I Plano Nacional de Educação, previsto para vigorar entre 1963 e 1970. O texto analisa o contexto que influenciou a concepção da educação pública cunhada por Anísio Teixeira e as influências recebidas na definição das metas com relação à educação e ao planejamento. O plano foi incorporado a partir de 1963 pelo Plano Trienal do governo João Goulart, sendo interrompido em 1964. Os autores concluem que o I PNE, ao contrário do que se apregoa, esteve vinculado a uma estratégia de País e a uma ancoragem econômica, que o teria viabilizado.

O outro artigo sobre política educacional intitula-se "Políticas inovadoras para o ensino médio no Brasil: um estudo de caso do ProEMI" e analisa o Programa Ensino Médio Inovador (PROEMI) no estado do Espírito Santo, no período entre 2012 e 2016. Sob a perspectiva da análise cognitiva de políticas públicas, as autoras analisam os dados coletados em cinco escolas da rede estadual, com entrevistas, grupos focais e a aplicação de um survey. Concluem que a implantação do ProEMI ocorreu de acordo com a 
realidade do sistema educacional e de cada escola. Para os participantes da pesquisa, o recebimento dos recursos financeiros e sua gestão proporcionou aos docentes e a seus estudantes experiências até então não vivenciadas por esses sujeitos, novas relações de trabalho e de perspectivas de ensinoaprendizagem. As autoras destacam, por fim, que tal política foi algo novo, simbólico e representativo do investimento estatal no ensino médio.

No artigo "Agroecologia e Pedagogia da Alternância: um estudo de caso da Escola Tecnológica de Fraiburgo, Santa Catarina", os autores apresentam pesquisa que analisou como o ensino de Agroecologia, em Pedagogia de Alternância, tem influenciado no ensino-aprendizagem dos estudantes e afetado o âmbito familiar e comunitário. Com base em análises às respostas a questionário aplicado a estudantes e em entrevistas com estudantes, professores, pais e pessoas ligadas à fundação da escola, os autores chegam a algumas conclusões. Afirmam que, se, por um lado, a aplicação do método "Tempo Escola e Tempo Comunidade" da Pedagogia da Alternância mostrou-se efetivo para articular escola, família e comunidade, podendo influenciar positivamente formas de cultivo, por outro, há uma distorção entre as práticas agrícolas locais e o ensino de Agroecologia, o que demanda uma transição de práticas tradicionais para práticas agroecológicas.

$\mathrm{O}$ artigo "O sentido do brincar e do jogar na infância humana como fundamentos à construção da democracia social" encerra a seção de estudos. Os autores discutem sobre o sentido elementar do brincar e do jogar, no período de desenvolvimento da infância do ser humano, como elementos fundamentais à educação cidadã democrática. A investigação é baseada em revisão bibliográfica e teórica de Mead (2010), Casagrande (2014), Kischimoto (2011) e Maturana (1994). Os autores concluem que a convivência democrática se constitui por ser fundamentalmente educativa, educando as crianças pela compreensão, pelo diálogo, pelos acordos, pelo tomar consciência, pelo corrigir o erro como algo construtivo e de aprendizagem.

Na seção Relatos de Experiência, são apresentados dois artigos. No artigo "Enriquecimento para um aluno com altas habilidades/ superdotação na educação infantil", as autoras relatam e analisam a aplicação de um Plano de Ensino Individualizado de Enriquecimento Tipo I a uma criança identificada com altas habilidades/superdotação na educação infantil. Concluem que as atividades de Enriquecimento do Tipo I contribuíram para o desenvolvimento das habilidades do aluno, além de mostrar os desafios desse tipo de atendimento para alunos com altas habilidades/superdotação da educação infantil.

Fechando o número 262 da RBEP, encontramos o artigo "As vivências como metodologia de ensino da extensão rural: a aproximação entre estudantes e agricultores para a compreensão da realidade social", no qual os autores apresentam e refletem sobre uma experiência de incorporação da vivência no modo de fazer a extensão. A extensão, como componente curricular, é problematizada pelos autores, afirmando as contribuições 
da inclusão da vivência como caminho de formação crítica. A atividade foi desenvolvida junto ao curso técnico em Agropecuária, modalidade subsequente do Colégio Politécnico da Universidade Federal de Santa Maria/ Rio Grande do Sul (UFSM/RS). O conteúdo foi desenvolvido com alternância de aulas teóricas e vivências em propriedades da agricultura familiar do município de Agudo/RS, organizado em conjunto com a prefeitura e a Empresa de Assistência Técnica e Extensão Rural (Emater-RS/Ascar), considerando etapas de ensino-aprendizagem por meio de reflexões com a realidade.

Desejamos a todos(as) uma leitura profícua e inspiradora!

Alexandre Filordi de Carvalho (Ufla) André Vitor Fernandes dos Santos (Inep) Claudianny Amorim Noronha (UFRN)

Elenita Gonçalves Rodrigues (Inep) Juarez José Tuchinski dos Anjos (UnB)

Maria Clara Bueno Fischer (UFRGS) Maria do Socorro Alencar Nunes Macedo (UFSJ)

Editoria Científica 
